\title{
El fútbol riojano en el siglo XX: el Logroño Recreation Club y el Club Deportivo Logroño (1912-1931)*
}

\section{The Riojan Football in the 20th Century: Logroño Recreation Club \& Club Deportivo Logroño (1912-1931)}

\section{DAVID MOTA ZURDO}

Universidad Isabel I

Facultad de Humanidades y Ciencias Sociales

c./ Fernán González, 76

09003 Burgos (España)

david.mota@uil.es

\section{(iD}

\section{JAVIER ZÚÑIGA CRESPO}

Universidad de La Rioja

Departamento de Ciencias Humanas

Edificio Vives c./ Luis de Ulloa, 2

26004 Logroño (España)

javier.zuniga@unirioja.es

iD

RECIBIDO: FEBRERO DE 202

ACEPTADO: MARZO DE 2021

Resumen: El fútbol se introdujo en España en las últimas décadas del siglo XIX y se asentó como deporte de masas en el primer tercio del siglo XX. Fue un periodo lleno de altibajos: nacieron clubes nuevos y desaparecieron otros en un contexto donde se sucedieron las discusiones entre equipos y federaciones sobre cómo organizar la competición. Este artículo analiza cómo se consolidó el fútbol en la ciudad de Logroño a través de los dos clubes más influyentes de este tiempo: El Logroño Recreation Club y el Club Deportivo Logroño. Durante este periodo se crearon más equipos logroñeses, pero fueron los anteriormente citados los que fueron determinantes en la evolución del fútbol riojano. Por último, se estudian los problemas deportivos e institucionales que suscitó la incorporación de los equipos riojanos en la Federación Guipuzcoana de fútbol.

Palabras clave: Fútbol. Rioja. Logroño Recreation Club. Federación guipuzcoana. Club Deportivo Logroño.

Abstract: Football was introduced in Spain over the last decades of the 19th century and it was recognised as a mass sport in the first third of the 20th century. It was a period full of ups and downs: while some new clubs showed up, some others disappeared due to competition debates between teams and federations. The aim of this article is to analyze the football consolidation in Logroño throughout the most important football clubs of that time: Logroño Recreation Club and Club Deportivo Logroño. During this period more clubs appeared but they weren't as important for the Rioja's football development as the ones mentioned before. To end up, some sport and constitutional issues caused by the incorporation of the Rioja's teams into the Gipuzkoan Football Federation have been analysed.

Keywords: Football. Rioja. Logroño Recreation Club. Football Federation of Guipuzcoa. Club Deportivo Logroño.

\footnotetext{
* Esta investigación forma parte de un proyecto financiado por el Instituto de Estudios Riojanos en su convocatoria de 2020 de ayuda para estudios científicos de temática riojana titulado «El fútbol en La Rioja durante la Segunda República: un estudio de caso en perspectiva comparada de las localidades de Logroño y Haro (1931-1939)». Y del proyecto de investigación que dirige Coro Rubio Pobes en la UPV-EHU (PGC2018-094I33-B-I00 (MCIU/AEI/FEDER, UE).
}

MEMORIA Y CIVILIZACIÓN 24 (202I): 537-564 [I-28] [ISSN: II 39-0I07; ISSN-e: 2254-6367] 
DAVID MOTA ZURDO - JAVIER ZÚÑIGA CRESPO

\section{INTRODUCCIÓN}

Las primeras décadas del siglo $X X$ fueron las más importantes en la implantación del fútbol como deporte de masas en España, tanto en su práctica como en su disfrute. La formación de equipos y sociedades futbolísticas se sucedió por todo el territorio, convirtiéndose este deporte en uno de los más populares y en un espectáculo, que, en el caso riojano, llegó a eclipsar al resto de prácticas de ejercicio y recreo. Por eso, en este trabajo se estudia el proceso de consolidación de este deporte en la ciudad de Logroño a través de las dos entidades futbolísticas más representativas del primer tercio del siglo XX: el Logroño Recreation Club y el Club Deportivo Logroño.

Los inicios de estos dos clubes fueron difíciles porque, por un lado, este deporte careció inicialmente de apoyo institucional, y, por otro, recibió duras críticas en la prensa por su procedencia foránea y su agresividad. Como se verá a lo largo de estas páginas, no fue hasta 1912 cuando el fútbol se estabilizó en Logroño, gracias a la implicación de las élites mesocráticas locales que impulsaron la creación de entidades deportivas como el Logroño Recreation Club. Y que fueron las principales personalidades de la ciudad, muy bien situadas social y políticamente -algunas incluso cercanas al cacicato local-, las que vieron en este deporte un nuevo concepto de ocio. Fue así como se encendió la mecha del interés futbolístico en la capital riojana, ligando la identidad logroñesa a los valores defendidos por sus entidades deportivas.

Durante una década el club compitió y creció en popularidad, tanto a nivel local como nacional. Pero, al igual que muchos otros, en 1922 caería en desgracia, presa de una crisis institucional y económica. Cogió el testigo ese mismo año el Club Deportivo Logroño, una nueva sociedad deportiva con un ambicioso proyecto que, aunque tardó en despegar, se impuso a las adversidades y se consolidó como el equipo más importante de la ciudad. Con nuevo campo incluido, Las Gaunas, reconocible por cualquier aficionado al fútbol, el club empezaría a despegar desde las categorías más bajas, sumando ascenso tras ascenso.

Ante la ausencia de un circuito competitivo suficiente en la provincia de Logroño y la singular organización tanto del campeonato nacional de liga como de las competiciones regionales, el club riojano se vería abocado a competir en la Federación Guipuzcoana, ubicándose así dentro de la región vasca: un hecho que, como se verá en este artículo suscitaría debates y problemáticas diversas.

Este es, pues, un trabajo que parte de lo particular y que se basa en el estudio histórico de dos clubes de fútbol logroñeses. Sin embargo, no se constriñe a un análisis micro o local, sino que analiza las trayectorias de estos clubes 


\section{EL FÚTBOL RIOJANO EN EL SIGLO XX}

atendiendo a una serie de tendencias y procesos históricos que también afectaron a otras entidades deportivas nacionales. El objetivo último es arrojar algo más de luz a una cuestión insuficientemente estudiada por la historiografía riojana: la historia del fútbol logroñés durante el primer tercio del siglo XX.

\section{I.I. Metodología y Fuentes}

Este estudio sobre el fútbol logroñés entre los años 1912 y 1931 se basa en fuentes hemerográficas - La Rioja: diario político, Excelsior, Euzkadi, El Noticiero Bilbaíno, El Liberal y Logroño Deportivo: periódico semanal- y archivísticas -Archivo Histórico Provincial de La Rioja-, que son las principales para reconstruir la historia del fútbol en la capital riojana durante el arco cronológico elegido. También es fruto del análisis crítico de la bibliografía existente sobre el fútbol y la práctica deportiva centrada en este periodo histórico.

Por otro lado, el enfoque hermenéutico utilizado en este trabajo es fundamentalmente empirista, sin menoscabo de que la interpretación de las fuentes se realice por momentos y en función de su riqueza y profundidad desde la óptica de la historia social y de las identidades: una herramienta esencial para realizar un acercamiento a este espectáculo y deporte haciendo uso de los instrumentos propios de análisis de esta disciplina que estudia la sociabilidad, el ocio y las identidades colectivas. Asimismo, es de justicia reconocer que dado el práctico vacío historiográfico que hay al respecto sobre investigaciones deportivas en La Rioja, se ha optado por ofrecer apartados descriptivos que son necesarios para conocer el desarrollo de este deporte en Logroño.

\section{I.2. Estado de la cuestión'}

En las últimas décadas se han realizado importantes aportaciones a la historia contemporánea del deporte en España a través de distintas monografías, tesis doctorales y artículos científicos publicados en editoriales y revistas de primera línea. Prueba de ello son los trabajos pioneros de Milagros García, José María de Lucas, Manuel Vizuete, Francisco Calatayud, Javier Olivera o José Luis Pastor en los que hay una pluralidad de perspectivas a la hora de afrontar la historia del deporte, sobresaliendo de todas ellas el enfoque educativo ${ }^{2}$. Estos trabajos han coincidido con otros ensayos cuya perspectiva de análisis ha sido médica, como las tesis de Juan A. Mestre y Ana María Quirós, los trabajos de María Eugenia Martínez o el estudio de Francisco Gallardo. También, en paralelo, han visto la luz otros trabajos que se han centrado en la vertiente social del

\footnotetext{
I Las obras citadas en este apartado son una breve selección realizada de las más notorias e influyentes para esta investigación.

2 García Bonafé, 1986; De Lucas, 1998; Vizuete, 1996; Calatayud, 1998; Olivera, 1997; Pastor, 1997.
} 


\section{DAVID MOTA ZURDO - JAVIER ZÚÑIGA CRESPO}

fenómeno como son los de Francisco Lagardera y Jorge Uría, que aquí se tienen como referentes ${ }^{3}$.

La tónica de las publicaciones durante la década de los 2000 continuó caracterizándose por dedicar una especial atención al factor educativo para analizar la historia del deporte, como queda evidenciado con los trabajos de Lucio Martínez, Rafael Fernández-Sirvent o Miquel Robert. No obstante, en paralelo a estos estudios, comenzaron a publicarse otro tipo de ensayos que, recogiendo el testigo de Lagardera y Uría, han realizado aportaciones temáticas y metodológicas muy diversas a la historia del deporte - prensa, subdisciplinas deportivas, género, identidades, entre otros- como son los de Xavier Torrebadella, Eugenio Izquierdo, el ya citado Calatayud, Teresa González, Xavier Pujadas, Carles Santacana, Rodrigo Gil, Francisco J. Caspistegui, Fernando Estomba, Catalina Riaño (y de esta con Concepción Carbajosa), André Gounot, Manuel Zambrana, Antonio Rivero, José Tierra, José Ignacio Barbero, el ya aludido Uría, Luis Enrique Otero o Juan Antonio Simón 4 .

En los años del cambio de década, continuaron publicándose obras sobre el deporte que fueron de notable impacto como la de Carles Sirera o Andrés Domínguez. Sin embargo, fue a partir de la década del 2010 cuando los estudios sobre la historia del deporte experimentaron un auténtico boom. En 2011 se publicó Atletas y ciudadanos: historia social del deporte en España (I870-2010), una monografía referente sobre el deporte en este país por los tres pilares temáticocronológicos sobre los que está construida, que abarcan la mayor parte de la contemporaneidad. Esta obra fue coordinada por Xavier Pujadas y en ella participaron reconocidos investigadores que han dedicado su atención a esta temática dentro de sus líneas de investigación habituales como son Ángel Bahamonde, Juan Carlos Manrique, Sixte Abadía, Bernard López, Dominique Bodin, Ricardo Sánchez, Alejandro Viuda-Serrano o los ya citados Domínguez, Santacana, González y Pujadas. Ese mismo año se presentaron tesis doctorales notables sobre el deporte como la de Juan Antonio Simón, de un interés significativo para este trabajo, por centrarse en el fútbol durante el primer tercio del siglo XX, o la de Ricardo Leiva Román, entre otras. Pero, junto a ellas, se encuentran los trabajos previos y posteriores que se publicaron durante estas décadas por autores ya

\footnotetext{
3 Mestre, 1996; Quirós, 2010; Martínez, 2003, pp. 30-48; Gallardo, 2006, pp. 35-40; Lagardera, 1995-1996, pp. I5I-172; Uría, 1996.

4 Martínez, 2000, pp. 83-II2; Torrebadella, 2000, pp. II-2I; Izquierdo, 200I; Uría, 200I, pp. 65-68; Calatayud, 2002; González, 2003; Pujadas y Santacana, 2003, pp. 505-522; Otero, 2003, pp. 169-198; Gil, 2004; Caspistegui, 2004, pp. 129-174; Riaño, 2004; Gounot, 2005, pp. II5-123; Zambrana, 2005; Rivero, 2005; Barbero, 2006, pp. 69-93; Tierra, 2007, pp. 53-59; Fernández-Sirvent, 2007, pp. 24-5I; Estomba, 2007; Torrebadella 2009; Simón, 2009, pp. 77-102; Riaño y Carbajosa, 2009, pp. 23-47; Robert, 2010, pp. 52-61; Barbero, 2012, pp. 580-603; Otero, 2016, pp. 255-283.
} 
citados como los de Caspistegui y Santiago Leoné, María José Mateos, Juan Carlos Fernández, David Rodríguez, Beatriz Lorenzo o el citado Torrebadella 5 .

Los avances en la investigación en lo que se refiere a la historia del fútbol también han sido especialmente notorios, desde la interesante monografía de Duncan Shaw, Néstor Míguez y Paul Preston, el pionero trabajo de Carlos Fernández sobre el fútbol durante la Guerra Civil y el franquismo o el trabajo de Martialay sobre la profesionalización del fútbol y la creación del torneo de liga, hasta los trabajos sobre la historia de este deporte de autores como los citados en párrafos precedentes.

Tanto estos últimos como otros autores que se citan a continuación han publicado diferentes estudios generales y específicos sobre clubes y la implantación de este fenómeno deportivo en España desde múltiples perspectivas - historia de las identidades y/o las culturas políticas, género, historia local, microhistoria o historia de la arquitectura, entre otros-. Así sucede, por ejemplo, con los casos de Caspistegui y John K. Walton, Pujadas (y de este con Aleix Augé), Santacana, Bahamonde, Uría, Simón, Torrebadella (y de este con Carlos Pérez y Antoni Nomdedeu), José María Báez, Francisco Pinheiro, Pedro Ciria, Alejandro Quiroga, Ángel Iturriaga, Julio Antonio Yanes, Antonio José Cidoncha, Alejandro Camino o Santiago de Pablo6.

También el hecho de que durante estos años echaran andar revistas como Apunts. Educación fisica y deportes, Materiales para la Historia del Deporte, Revista Internacional de Ciencias del Deporte o Citius, Altius, Fortius: humanismo, sociedad y deporte: investigaciones y ensayos, impulsadas por algunos de los especialistas anteriormente citados, o que viera la luz Cuadernos de Fútbol, una publicación de divulgación científica en la que recurrentemente han aparecido trabajos de especialistas en la materia como Fernando Arrechea, Carlos Aiestaran o José Ignacio Corcuera, ha contribuido a que desde la década de 2010 a esta parte se haya producido una eclosión de estudios sobre temática deportiva.

En el ámbito riojano, las investigaciones sobre deporte y fútbol no han sido excesivamente abundantes, sobre todo en lo que se refiere a tener como objeto de estudio la sociedad riojana de los siglos XIX y XX. Sobresalen los trabajos de

\footnotetext{
${ }^{5}$ Sirera, 2008; Domínguez, 2009; Caspistegui y Leoné, 2010; Pujadas, 201 I; Simón, 201 I; Mateos, 2011, pp. 69. 88; Leiva, 2012; Fernández y Rodríguez, 2013, pp. III-122; Lorenzo, 2016. La producción historiográfica de Xavier Torrebadella es amplísima. Por eso, por cuestión de espacio, se remite directamente a su espacio personal de Dialnet.

6 Shaw, Míguez y Preston, 1987; Fernández, 1990; Martialay, 1996; Uría, 2008, pp. 12I-155; Caspistegui y Walton, 200I; Pujadas y Santacana, 200I, pp. 147-168; Báez, 20I2; Simón, 20I2a; Simón, 20I2b, pp. 69-84; Torrebadella, 2012, pp. 80-102; Ciria, 20I2; Pujadas y Augé, 20I2, pp. I23-143; Quiroga, 20I4; Pinheiro, 20I4, Pp. 2-10; Simón, 2015; Iturriaga, 2015; Yanes, 2015, pp. 164-186; Torrebadella y Nomdedeu, 2016, pp. II9146; Simón, 2016, pp. 45-63; Cidoncha, 2018; Camino, 2019, pp. I19-137; Quiroga, 2019, pp. 270-302; Torrebadella y Martínez, 2020; De Pablo, 2020a.
} 


\section{DAVID MOTA ZURDO - JAVIER ZÚÑIGA CRESPO}

Carlos Muntión, Andoni Fernández, Francisco Bermejo, Javier Castro, Sergio Andrés o los realizados por David Mota, uno de los autores de este artículo. De hecho, este ha profundizado recientemente en diferentes disciplinas del deporte riojano siguiendo los pioneros estudios de Bermejo y Fernández para hacer hincapié, principalmente, en cómo se urdió el tejido futbolístico entre los riojanos desde principios del siglo XX. Recogiendo el testigo de estas investigaciones sobre el deporte, con este artículo se pretende poner en evidencia la existencia de un interés creciente en la historiografía riojana por la historia del fútbol. En este sentido, con ánimo de mantener esta dinámica, este trabajo aspira a continuar profundizando en el fenómeno dedicando una atención preferente a la ciudad de Logroño ${ }^{7}$.

\section{EL FÚTBOL EN LOGROÑO DURANTE EL SIGLO XX}

2. I. De los primeros clubs a la creación del Club Deportivo Logroño (19/4-1922)

Los orígenes del fútbol riojano están ligados a la etapa de la Restauración, durante la que comenzó a difundirse el deporte moderno en la entonces provincia de Logroño. La Ley de Asociaciones de 1887 fue determinante en este punto, no sólo a nivel regional, sino nacional, ya que contribuyó a la proliferación de diferentes sociedades políticas, culturales y también deportivas. El deporte se convirtió así en una parte fundamental del ocio y la sociabilidad que practicaron las sociedades modernas, sobre todo, con su progresiva conversión en espectáculo de masas a principios del siglo XX y que, en concreto, en la provincia de Logroño, vino acompañada de un incremento de las relaciones socioeconómicas con los territorios limítrofes más próximos.

En efecto, los contactos de la provincia de Logroño con el País Vasco y Navarra, gracias al ferrocarril y la industria vinatera, contribuyeron, en parte, a que la capital riojana gozara de unas particularidades concretas y que se convirtiera en la garante de una serie de valores políticos y sociales que fueron reflejo de un determinado estatus mesocrático, cuando no elitista. Estos valores tuvieron su reflejo en el deporte, que se convirtió en un terreno de defensa de la identidad logroñesa frente a otras localidades de la provincia y de fuera de ella?

El fútbol fue el que mayor protagonismo tuvo en la vida cotidiana de la sociedad riojana $y$, por consiguiente, se convirtió en el principal espectáculo de

\footnotetext{
${ }^{7}$ Muntión, 1993; Fernández, 2004a, pp. 22I-236; Fernández, 2004b; Bermejo, 2009; Andrés y Castro, 20II; Castro, 2015, pp. 135-148; Mota, 2019a; Mota, 2019b, pp. 78-93; Mota, 2020a, pp. 137-160; Mota, 2020b, pp. 19-35; Mota, 2020c; Mota, 2020d; Mota, 2020e.

8 Simón, 2014, p. 99; Climent, 200I, p. 215; Moreno y Sancho, 2004, pp. 199-200.

9 Cañas, 2013, p. 159; De la Fuente y Calvera, 2014; Vizuete, 2009, pp. 31-32; Souto, 2013, pp. 163-178.
} 


\section{EL FÚTBOL RIOJANO EN EL SIGLO XX}

masas durante el primer tercio del siglo $X X$. Como en el resto de España, fue desde principios de la centuria una actividad muy popular y así quedó reflejado en la prensa local durante los primeros años de la década de 1900, en los que hay numerosos artículos sobre higienismo y educación física. A partir de 1910, se publicaron tanto la crónica de partidos y su organización por asociaciones de todo tipo como artículos sobre la importancia del deporte y el fútbol para la regeneración nacional de España. Junto a ellos se editaron otros que simplemente dieron un toque de atención crítico a los logroñeses para que se volcaran en la práctica deportiva, reprobando de paso a un deporte foráneo como el fútbollo.

Sin embargo, estas recurrentes críticas no fueron suficientes como para que la sociedad riojana desatendiera esta práctica. Durante la década de 1910 se constituyeron varias entidades recreativas en Logroño: Gran Casino, Círculo Logroñés y el Círculo La Amistad, que, a la postre, fueron fundamentales para la proliferación del deporte $y$, más concretamente, del fútbol en la capital. Las dos entidades deportivas principales de la localidad fueron la Sociedad Deportiva Logroñesa, fundada en 1910, que al año siguiente se convirtió en la Agrupación Deportiva Gran Casino por su fusión con la sociedad Gran Casino, y el Logroño Recreation Club, que se creó en 1912. Estos dos clubes fueron los impulsores del fútbol en Logroño, pero se enfrentaron a diferentes obstáculos. Carecieron de respaldo institucional y las críticas vertidas por determinados periodistas de La Rioja: diario político contribuyeron a generar oposición hacia este deporte, tildándolo de exótico por su procedencia extranjera y de salvaje por la brutalidad de algunos lances del juego'".

Con todo, el fútbol se abrió paso en Logroño de forma inexorable a partir de junio de 1912, cuando se constituyó oficialmente como sociedad deportiva el Logroño Recreation Club. Este contó con el apoyo de las personalidades más destacadas de la ciudad y del cacicato local, como queda evidenciado por la composición de su junta directiva presidida por Juan José Díaz Quincoces y Saturnino Aragón. Se articuló en diferentes secciones deportivas, de la que sobresalió su rama futbolística, y su directiva se volcó en la creación de un espacio (un estadio) para su práctica y celebración de partidos y fiestas con el objetivo de crear un exclusivo club social. La decisión de disponer de un campo propio y el apoyo de la prensa fueron fundamentales para que la ciudadanía fuera inoculada con el virus de la afición por el fútbol. Precisamente, la prensa jugó un papel clave durante

\footnotetext{
10 Fernández, 2004a, pp. 22I-236. En cuanto al higienismo en La Rioja ver Mota, 2020d. Sobre estos artículos en los que se recomendaba la práctica deportiva como fundamento para la mejora racial, ver Mota, 2020c, Pp. 39-47.

$1 /$ Fernández, 2004a, pp. 226. En sus editoriales, el periodista Gorrochategui no se explicaba cómo el fútbol podía tener tantos partidarios «como una corrida [de toros]», La Rioja, 05 de febrero de I9I I, p. I. La Rioja, 23 de abril de I9II, p. I.
} 


\section{DAVID MOTA ZURDO - JAVIER ZÚÑIGA CRESPO}

estos primeros años: informó periódicamente de la situación del club y sus eventos, además de que en sus páginas se dieron cita tanto los enfrentamientos entre clubes de la localidad — con la Agrupación Deportiva Gran Casino- y de estos con otros de municipios riojanos y/o vascos y navarros ${ }^{12}$.

A la par, el Recreation también se preocupó por crear su sello distintivo que le otorgara una identidad propia vinculada a la capital riojana. Fijó los colores del club y otros símbolos como el diseño de la camiseta y su insignia para representar «la bandera de nuestro pueblo». Los colores elegidos fueron el blanco, el rojo y el azul, presentes en la bandera (cruz roja de San Andrés sobre fondo blanco) y en el escudo de Logroño. En menos de dos años, Logroño Recreation Club compitió por primera vez en el campeonato de España de segunda categoría tras proclamarle campeón riojano la Federación Nacional de Fútbol. Asimismo, instó a la Agrupación Deportiva a que tomara parte en estos campeonatos ${ }^{13}$.

Durante la década de 1910 ambos clubes concertaron partidos amistosos con equipos vascos, navarros y aragoneses como el Jolastokieta, el New Club, el Tudela y la Gimnástica Zaragozana, e impulsaron competiciones locales como la Copa de Navidad con el objetivo de que se creara afición por el fútbol en Logroño. Sin embargo, este empuje se vio continuamente azotado por los altibajos y las irregularidades, restando posibilidades a la implantación y continuidad del fútbol en la localidad. Así lo reflejó Fernando Salvador en la revista Stadium al denunciar en 1916 que la Agrupación Deportiva había vivido demasiado tiempo inactiva y que el Logroño Recreation Club, por su falta de iniciativa, había experimentado una reducción del número de socios por desazón y desánimo ${ }^{14}$.

Por eso, ese mismo año, mientras la Agrupación Deportiva se mantuvo inmóvil, siendo a la postre clave para su relegación a un plano subsidiario, la directiva recreationista, presidida por Francisco Íñiguez, exalcalde de la localidad, inició gestiones con la Real Federación Española de Fútbol (RFEF) para que la final del campeonato regional se celebrara en Logroño. Sin embargo, esta nunca se celebró: la RFEF había tratado de saltar por encima a una institución «amiga», la Federación Regional Norte (FRN), que ya había otorgado el triunfo al Athletic Club de Bilbao por incumplimiento del reglamento por parte del otro finalista, la Real Sociedad de San Sebastián. Los esfuerzos, en cambio, no fueron en vano: demostraron que la directiva tenía que aprender a moverse entre los pasillos

\footnotetext{
12 Díaz Quincoces, militar natural de Briones, destinado en el 12 regimiento de la guarnición de Logroño. Saturnino Aragón, por su parte, era un abogado de ideología liberal que fue concejal del Ayuntamiento de Logroño durante la Restauración y presidió el Círculo Logroñés. Ibarnavarro, 1946, pp. 102-103; López. 1999, p. 205; La Rioja, 18 de octubre de 1922, p. 2. La Rioja, 29 de junio de 1912, p. 2. Sobre la enemistad entre los clubes riojanos ver Mota, $2019 \mathrm{~b}$.

13 La Rioja, 3 de agosto de 1912, p. 2; La Rioja, 23 de abril de 1914, p. 2.

14 Mota, 2020c, pp. 7I-83; La Rioja, 12 de febrero de 1916, p. 2.
} 


\section{EL FÚTBOL RIOJANO EN EL SIGLO XX}

federativos $y$, de paso, establecer una adecuada programación de partidos que contribuyeran a la fiebre futbolística ${ }^{15}$.

Partido a partido, el Recreation fue curtiéndose en competiciones deportivas hasta establecer una alineación competente y capaz de hacer un buen papel, sobresaliendo el siguiente once: M. Erice, G. Erice, Colmenares, V. Redón, Errea, Deus, Sáinz, J. Erice, Pita, Redón e Irazusta. Pero, en el otoño de 1916, tras realizar las gestiones para incorporar al club a los campeonatos de más alto nivel, recibió un duro golpe: la FRN rechazó inicialmente su inscripción en el campeonato de España de segunda categoría aduciendo que sus jugadores incumplían el requisito de antigüedad, a saber, que su participación en el club superara el año. La prensa riojana se volcó en críticas hacia esta decisión que a su juicio era incomprensible y arbitraria. Pocas semanas después, coincidiendo con el cambio de la junta directiva de la FRN, la institución federativa cambió de opinión e incluyó al Recreation en la serie B del campeonato guipuzcoano, que comenzó en la primavera de 1917. Durante esta primera convocatoria, su paso por la competición no fue muy notable: derrotó al conjunto navarro del Amaya después de tres partidos, pero perdió contra el guipuzcoano Izarra. Si bien, en la siguiente temporada, terminó semifinalista de primera categoría de la serie B, siendo este su principal logro 16 .

A pesar de que Logroño Recreation Club no obtuvo copa alguna, ni venció en ningún campeonato, su papel fue fundamental para afianzar la afición al fútbol en la capital riojana y difundir fuera de su territorio la pasión riojana por el fútbol. El club desapareció en diciembre de 1922 sumergido en una profunda crisis económica, institucional y deportiva, coadyuvada por el hecho de que «el propietario del campo [de fútbol de La Trilladora, en el que jugaba Recreation] así lo dispuso». Fue, por tanto, un proyecto futbolístico, como muchos otros de estos años que no pudo sobrevivir a la dinámica de partidos y campeonatos que exigió este deporte de masas ${ }^{17}$.

Con todo, su impronta quedó grabada en la sociedad riojana aficionada al deporte, siendo el acicate para la germinación de otros clubes senior de la capital riojana y del resto de la provincia como el Club Deportivo Logroño -denominado en primera instancia Club Deportivo España F.C. de Logroño-, que se fundó en otoño de 1922 en sustitución de Recreation y que se impuso como la principal entidad deportiva riojana frente a otros clubes como Haro Sport Club

\footnotetext{
15 Mota, 2020c, p. 74.

16 La Rioja, 30 de junio de 19|3, p. I; La Rioja, 2 de junio de 1917, p. 2; La Rioja, 9 de junio de 1917, p. I; La Rioja, 13 de diciembre de 1917, p. 2.

${ }^{17}$ Euzkadi, 4 de octubre de 1928, p. 4.
} 


\section{DAVID MOTA ZURDO - JAVIER ZÚÑIGA CRESPO}

- Club Deportivo Calahorra. En Navarra y, concretamente, en Pamplona, sucedió algo similar. Según Francisco J. Caspistegui, Osasuna se erigió como el club representativo de la provincia «favorecido por su mayor capacidad de control futbolístico en la reducida comunidad pamplonesa de los años veinte» 18 .

Pero el hecho de que la nueva denominación del club insignia de la capital riojana fuera en castellano evidencia un proceso generalizado de cambio y búsqueda de vinculación identitaria más potente que en etapas precedentes. Puede parecer algo banal, pero el hecho de que la denominación del club fuera reconocible para la población local permitió establecer nexos más estrechos entre el club y la sociedad y, por consiguiente, reforzar su sentimiento de pertenencia. Así sucedió, por ejemplo, en provincias limítrofes como Álava, donde el Sport Friend's Club, una sociedad futbolística creada por aficionados vitorianos en 1920, optó por cambiar de nombre en enero de 1921, para pasar a denominarse Deportivo Alavés 19.

Si bien, aun atendiendo las cuestiones apuntadas, se debe reconocer que Logroño Recreation Club fue el motor futbolístico riojano, y así sería recordado por la prensa varios años después, cuando el cronista futbolístico Zancadilla señaló en el diario deportivo Excelsior: «que el Deportivo Logroño es una continuación del Recreation, que fue fundado y dado de alta el año $|9| 2 »\rangle^{20}$.

2.2. El Club Deportivo Logroño durante la Dictadura de Primo de Rivera (19231931)

Inicialmente, la historia del Deportivo Logroño se vio trufada de obstáculos. Según Prudencio y Arraiz, entre noviembre de 1922 y diciembre de 1923, el club se limitó a jugar encuentros con equipos de otras categorías de provincias limítrofes mientras use resolvían los distintos trámites burocráticos y económicos». De estas palabras se infiere que el Deportivo, como continuador del Recreation, tuvo que ingeniárselas para afrontar las deudas de Recreation, pues continuó jugando en el campo de la Trilladora; sanear las arcas del club estableciendo de inicio una cuota fija de afiliación; $y$ entablar gestiones con las autoridades municipales para hacerse con un terreno e iniciar la construcción de un estadio (Las Gaunas) que estuviera a la altura de sus aspiraciones futbolísticas. Esta es una hipótesis plausible que se infiere de lo apuntado por otros autores como los ya citados y lo indicado por la prensa de la época. En un suelto del Noticiero Bilbaíno de octubre de 1923 quedó en parte así reflejado:

\footnotetext{
18 Caspistegui, 200I, p. 196.

19 De Pablo, 2020b, p. 240; Caspistegui, 2012.

${ }^{20}$ Archivo Histórico Provincial de La Rioja (AHPLR), Gobierno Civil, Libro de Registro de Asociaciones, Legajo 242; Prudencio y Arraiz, 1990, p. 8; Bermejo, 2009, p. 154.
} 


\section{EL FÚTBOL RIOJANO EN EL SIGLO XX}

Necesitando esta Sociedad cercar los terrenos donde ha de establecer sus Campos de sport, se admiten «proposiciones y proyectos» de cerca, teniendo en cuenta que el perímetro del campo será de 800 metros lineales, debiendo tener la cerca 2,50 metros de altura aproximadamente, sin incluir el correspondiente cimiento. En las proposiciones deben indicarse los materiales que se emplearán en la construcción procurando [que] sean los de más duración dentro de la mayor economía. También se advierte a los señores anunciantes y empresas de publicidad, que dada la situación del campo se presta dicha cerca para fines de propaganda pudiendo hacer proposiciones en este sentido. Las ofertas deben dirigirse al señor secretario del Club don Ramón Martínez [...] reservándose la Junta aceptar la que crea más conveniente o desecharlas todas ${ }^{2 !}$.

Después de diferentes gestiones y licitaciones, el campo de sport de Las Gaunas se terminó de construir en 1924, inaugurándose en junio de ese año con un partido contra el equipo francés de Vie au Grand Air du Médoc, en el que los logroñeses vencieron tres a cero. Sin embargo, la inauguración oficial se realizó en septiembre. La directiva del equipo riojano se volcó en busca de un club reconocido e histórico, que atrajera público y marcara un antes y un después en la trayectoria del fútbol local. Recreation ya había inaugurado en su día su estadio con un partido entre el Español de Barcelona y el Racing Club de Irún, por lo que un estadio como Las Gaunas debía contar como mínimo con un club similar que estuviera a la altura, como quedó recogido en El Liberal.

Para el día 24 del corriente mes se anuncia la inauguración del campo de deportes del Club Deportivo de Logroño. Contenderá un equipo del Athletic de Bilbao. El que ha de enfrentarse con los rojiblancos no lo sabemos todavía. Se creía que sería la Real Unión, de Irún, pero aún se desconoce si serán éstos o una selección la que jugará contra el Athletic ${ }^{22}$.

Finalmente, siguiendo lo señalado por Prudencio y Arraiz, el equipo que inauguró el estadio fue, por un lado, un combinado del Real Unión de Irún y el C. D. Logroño, y, por otro, el Athletic Club de Bilbao, del que el conjunto vizcaíno salió vencedor por cuatro goles a dos. Fue un partido que recibió una gran acogida y en el que participó el alcalde de la localidad, Antonio Tomás Hernández, que hizo el saque de honor ${ }^{23}$.

La andadura del conjunto riojano por los campeonatos federativos comenzó en el otoño de 1925. El club se inscribió en la serie C de la Federación Guipuzcoana y ese mismo año se proclamó campeón y ascendió a la serie B. Ese año disputó cerca de treinta encuentros cosechando multitud de victorias, tres

${ }^{21}$ El Noticiero Bilbaíno, 12 de octubre de 1923, p. 6; Prudencio y Arraiz, 1990, p. 8.

22 El Liberal, 13 de septiembre de 1924, p. 4.

23 Prudencio y Arraiz, 1990, p. 8. 


\section{DAVID MOTA ZURDO - JAVIER ZÚÑIGA CRESPO}

empates y tres derrotas. Una de esas derrotas la sufrió en un amistoso contra el equipo bilbaíno Acero Club de Olaveaga que venció por ocho goles a cero al club logroñés, incapaz de demostrar dotes futbolísticas. La crónica de aquel partido es ilustrativa de que al club riojano aún le faltaban partidos importantes para ponerse a tono competitivo, como quedó recogido en el diario nacionalista vasco Euzkadi:

El campo de las Gaunas, propiedad del Club Deportivo Logroño, ha sido escenario de la tremenda victoria conseguida por el club bilbaíno. El público que asistió al encuentro, en el que se destacaban infinidad de señoritas riojanas, ha dado una prueba más de cultural. Arbitró el colegiado aragonés Adrados, que lo hizo a la perfección. Los equipos se presentaron en el campo en medio de grandes ovaciones. Tan pronto como se ha comenzado el partido, se ha hecho manifiesto el dominio acerista. A los pocos momentos de juego Labaca, que se ha escapado, internándose, cruza muy bien un balón y consigue el primer tanto. Se suceden algunas escapadas riojanas sin inquietar, y Teófilo, en un avance, consiguió marcar brillantemente el segundo goal. El tercero y cuarto son introducidos por Calero, poniendo a contribución sus entusiasmos. Con este resultado termina el primer tiempo. En el segundo tiempo, el Acero muestra nuevamente su potente juego y consigue con el dominio manifiesto que posee marcar otros cuatro goals más. Pertenece el primero de este segundo tiempo a Teófilo, que, hábilmente, sortea a los defensas riojanos, y coloca suavemente el balón en la red. También es Teófilo nuevamente el que repite otra vez la hazaña, jugando bien la cabeza en un centro de Labaca. El séptimo lo logra San Cristóbal, y antes de terminar el partido cierra el triunfo Labaca, introduciendo el octavo goal. Después del partido el numeroso público que lo presenció no sabía cómo considerar a los aceristas por tan brillante actuación. En Logroño no se deja de hablar de su juego ${ }^{24}$.

En las dos siguientes temporadas, la de 1926-1927 y la de 1927-1928, el Deportivo Logroño militó en la serie B, realizando actuaciones brillantes en los partidos de su segundo año en la citada división, derrotando al Lagun Artea de Pamplona, el Amaikak Bat de Deba o la Cultural de Durango. El siguiente extracto obtenido de la crónica del partido contra el equipo vizcaíno anteriormente citado es una buena muestra de su evolución progresiva y ascendente: «Las victorias del equipo riojano sobre el Indauchu y el Deusto, han de ser el toque de alerta para la Cultural [de Durango] que se desplazará completo con el fin de no correr la misma suerte». Durante esta temporada nombres como los de Miguelín, Bayón, Alcalde, Omist, Juliac y Pastor serían clave en las victorias del conjunto logroñés y en su posterior proclamación como campeón de la serie B guipuzcoana tras disputar la final al Euskalduna de Rentería ${ }^{25}$.

\footnotetext{
${ }^{24}$ Euzkadi, 30 de septiembre de 1924, p. 7.

25 Excelsior, 4 de octubre de 1927, p. 3; 28 de enero de 1928, p. 2; y 20 de marzo de 1928, p. 6.
} 


\section{EL FÚTBOL RIOJANO EN EL SIGLO XX}

Esta victoria no sólo le aupó a la serie A de la Federación Guipuzcoana, sino que fue un punto de inflexión en su posterior trayectoria y tratamiento por parte de la prensa y el resto de los clubs, que le verían a partir de entonces como un igual. De hecho, su victoria en partido amistoso contra el Arenas de Guecho, un club histórico, días después de proclamarse campeón de la serie, confirmó su nuevo estatus: el C. D. Logroño había sido «elevado a la altura de los grandes clubs guipuzcoanos» ${ }^{26}$.

No fue el único motivo por el que dejó de ser considerado un neófito en lo futbolístico. Días después, con motivo de la celebración de un partido amistoso con el Athletic Club de Bilbao (Junior), la prensa deportiva reforzó la idea apuntada de que el Deportivo Logroño era un club a tener en cuenta en la competición y para muestra el siguiente botón:

No podemos adelantar impresiones sobre el equipo riojano. No le hemos visto jugar esta temporada. Pero debe ser cosa bastante seria. Primeramente, porque en el campeonato ha ganado a pulso su victoria final. Después, porque el domingo pasado a un equipo del Arenas bastante fuerte le hizo [de]gustar en su campo de Las Gaunas el amargor de una derrota. A juzgar por los triunfos que alcanzan en su campo es un once terrible. Esperaremos a que en San Mamés se consagre ${ }^{27}$.

Esta serie de buenos resultados contribuyó de manera clave en aumentar el entusiasmo que la población logroñesa sentía por el fútbol. Como muestra de ello, nacieron en estos años diversas aventuras periodísticas relacionadas con el Deportivo Logroño. En noviembre de 1927 se creó el semanario Logroño Deportivo, órgano de prensa oficioso del C. D. Logroño, con el objetivo de ofrecer un análisis de «toda clase de deportes de los principales Clubs de España y en particular de todos los que se relacionen a la provincia y su Región» ${ }^{28}$.

Esta ambiciosa empresa estuvo lejos de ser real, porque no se dedicó a lo señalado: el citado boletín, impulsado por los propios aficionados del C. D. Logroño, se utilizó fundamentalmente para reflejar sus aspiraciones futbolísticas y en segunda instancia para hablar de manera genérica sobre el deporte. Santiago Leoné ha destacado una situación similar para Pamplona, señalando que la prensa navarra apoyó con práctica exclusividad a Osasuna porque fue el equipo más importante de la provincia y el representante de la ciudad navarra en el exterior ${ }^{29}$.

\footnotetext{
${ }^{26}$ Excelsior, 4 de abril de 1928, p. 2.

27 Excelsior, 7 de abril de 1928, p. 2.

28 Logroño Deportivo. Periódico semanal, 5 de noviembre de 1927.

${ }^{29}$ Leoné, 200I, Pp. 181 y 183.
} 


\section{DAVID MOTA ZURDO - JAVIER ZÚÑIGA CRESPO}

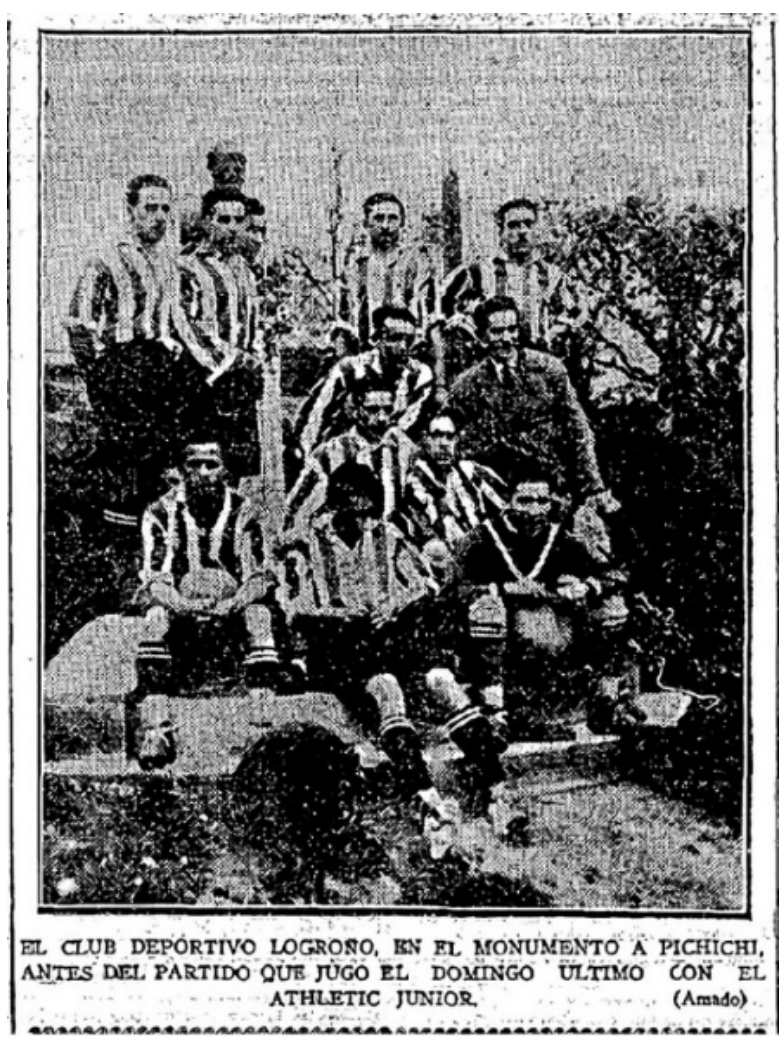

Figura I. Foto del Club Deportivo Logroño en San Mamés junto al busto de Pichichi. Fuente: Excelsior, 10 de abril de 1928, p. 5.

Pero retomando la publicación riojana, una prueba de que Logroño Deportivo se volcó solo con el club de la capital es el siguiente extracto:

La importancia deportiva de un pueblo o de una capital, está en relación directa con el número de deportistas, $y$ es directamente proporcional el beneficio físico y material, el que se obtiene. El hecho de que el equipo del C. D. L. pase a la serie A será causa fundamental de que la afición se extienda, pues viendo buenos encuentros, será como el público se dejará arrastrar por la avalancha deportiva, y Logroño llegará a ser un nombre, que dentro de los Centros deportivos se pronunciará con respeto y cariño ${ }^{30}$.

También en la siguiente afirmación:

30 Logroño Deportivo. Periódico semanal, 12 de noviembre de 1927. 


\section{EL FÚTBOL RIOJANO EN EL SIGLO XX}

Limpiamente, sin una sola derrota, sin un empate, el once logroñés ha conquistado el puesto de campeones de su serie, del distrito Rioja Navarra de la Federación Guipuzcoana. Honradamente, sin trabajos de zapa, presentándose a lucha noble, nuestro equipo ha vencido porque tenía que vencer; porque es superior a sus contrarios en deportivismo, en codicia, en técnica, $y$, en una palabra, es superior en todo ${ }^{31}$.

El Deportivo Logroño venció a los bilbaínos por cinco tantos a dos, recibiendo el equipo vizcaíno duras críticas de parte de la prensa deportiva local que consideró a los jugadores vascos indignos de portar la camiseta de un «club de rancio abolengo» como el Athletic Club de Bilbao al haber jugado contra los riojanos como si se tratara de «esos charlotescos partidos de solteros y casados en que gente de buen humor pretende pasar un rato divertido» ${ }^{32}$.

Aquella victoria fue una de las muchas cosechadas contra equipos de larga trayectoria futbolística. A los triunfos contra el Athletic Club de Bilbao y el Arenas de Guecho se sumó el de Osasuna, al que arrolló en Pamplona según las crónicas. Estas buenas actuaciones hicieron que la prensa dedicara largas noticias y le comparara con el Deportivo Alavés, que durante su primer año en la serie A vizcaína fue un equipo temible. Así las cosas, ante la participación del Deportivo Logroño en la serie A guipuzcoana, que se materializaría en la temporada 1928 1929, el equipo riojano demostró en los partidos amistosos contra estos clubes «con solera» que era «un buen equipo, sin ases y sin historia, pero un excelente conjunto» ${ }^{33}$.

Por este motivo, el club riojano reforzó sus filas ante el inicio de la serie A guipuzcoana formando el siguiente plantel: Omist, Ezquerro y Zuazo (porteros); Alcalde, Recarte, Vidal, Garriga, Tomás Sáenz y Suberviola (defensas); Poli, Sotés, Santín, Irazu, Cambra y Herrero (mediocentros); y Esturo, Ferrerín, Escolá, Arturo, Pastor, Araujo, Simón, Juliac, Miguelín, Ozaeta, Lerín, Llopis, Lecea, Isidoro, Pascual y Buznego (delanteros). Como si se tratara de uno de «los grandes del fútbol», el Deportivo Logroño hizo varias incorporaciones procedentes de clubs de diferentes puntos del norte de la península. Entre los señalados se encontraban jugadores fichados del Real Unión de Irún, del Osasuna, del Sporting de Gijón, del Portugalete, del Español de Barcelona, del Acero Club de Olaveaga y del Emden Foot-ball Club (equipo de La Coruña) ${ }^{34}$.

Aparte de los fichajes, con los que el Deportivo Logroño quería consolidarse en la primera categoría con un equipo competitivo, el club se propuso

\footnotetext{
31 Logroño Deportivo. Periódico semanal, 10 de diciembre de 1927.

32 Excelsior, 10 de abril de 1928, p. 5.

33 Excelsior, 5 de junio de 1928, p. 3; Euzkadi, 9 de junio de 1928, p. 4; Euzkadi, 10 de junio de 1928, p. 6.

34 Excelsior, 19 de agosto de 1928, p. 5.
} 


\section{DAVID MOTA ZURDO - JAVIER ZÚÑIGA CRESPO}

reformar Las Gaunas y convertirlo en un estadio de gran aforo al estilo de Atocha - San Mamés, como recogió el cronista Zancadilla para Excelsior:

El magnífico campo de deportes Las Gaunas, propiedad del Club Deportivo Logroño, está sufriendo en su terreno de juego una reforma tan rápida como necesaria. La promesa hecha por el ayuntamiento de llevar las aguas al campo es hoy una hermosa realidad. Las pruebas realizadas dieron el más satisfactorio resultado, y hoy cuenta el campo logroñés con siete bocas de riego, que permitirán en todo tiempo darle a la hierba, cuya siembra se hará uno de estos días, la humedad y frescura necesarias para su conservación y duración. La parte destinada a los espectadores es muy probable que sufra alguna variación y si la cabida de hoy, tal como está puede calcularse en $10000 \circ 12000$ almas, bien colocadas, esta reforma aumentaría en unos cuantos millares de cabida. Así pues, en estos tres meses el campo de Logroño va a sufrir una transformación tal, que nos permite asegurar será uno de los mejores de España ${ }^{35}$.

Sin embargo, los preparativos del Deportivo Logroño para su participación en la serie A no fueron un camino de rosas. En agosto de 1928, el secretario general de la RFEF, Ricardo Cabot, promovió la reforma del reglamento de la Federación Española centrándose en tres puntos principales que afectaron a los equipos integrados en las Federaciones de Vizcaya y Guipúzcoa. Las enmiendas promovidas por el organismo federativo conllevaron la reformulación de los grupos que constituirían la primera categoría de las federaciones regionales, la organización de estas instituciones y el establecimiento del calendario del campeonato de España. En concreto, los cambios afectaron al número de clubs que por cada región competirían en primera categoría, que pasaron de seis a cuatro, salvo en Cataluña que se mantuvieron los seis. Así, por ejemplo, en Vizcaya, se descendió por decreto al Acero Club de Olaveaga y se impidió el ascenso del Basconia. La prensa vasca, muy elitista tanto a la hora de valorar la reforma de Cabot como de considerar que las federaciones vizcaína y guipuzcoana estaban por encima de otras de más reciente creación como la extremeña o la castellanoleonesa, fue muy clara al respecto:

¿Está segura la Ponencia de que el Indarra, el Izarra, el Burgos, el Astillero, el Eclipse, el Lorca, etcétera, son clubs de Primera Categoría, y que, por el contrario, no lo es el Acero? Muy difícil les sería a los ponentes demostrarlo...que es imposible. iPor qué, además, asignar a Castilla León y a Extremadura los mismos clubs de primera categoría que se asignan a Guipúzcoa y Vizcaya? Si Cataluña tiene, por excepción, seis Clubs ipor qué estas regiones no tienen también por excepción

\footnotetext{
35 Excelsior, 3 de junio de 1928, p. 2.
} 


\section{EL FÚTBOL RIOJANO EN EL SIGLO XX}

tres o dos? ¿Es que el foot-ball de Extremadura es igual que el foot-ball de Vizcaya o de Guipúzcoa? ${ }^{36}$.

En este mismo artículo, criticó de paso que el Deportivo Logroño estuviera encuadrado en el fútbol vasco, reflejando, por otro lado, una realidad: el importante desembolso que suponía a los clubs de esta federación (y de muchas otras) tener que realizar largos desplazamientos para disputar los partidos de campeonato. Una situación que, dada la distancia y dificultades de conexión viaria entre, por ejemplo, Logroño e Irún, provocaba que los clubs más modestos, los que no cosechaban victorias habitualmente o los que no recibían el apoyo asiduo de los aficionados en su estadio vieran mermadas sus arcas:

[...] se le ha ido el santo al cielo al formar la región guipuzcoana con el Real Unión, la Real Sociedad, el Tolosa y el Logroño, que es algo como, por ejemplo, al Sporting de Gijón se le asignara como residencia la Federación Vizcaína, y se viera obligado a atravesar toda Cantabria para venir a jugar aquí el campeonato... ¡vizcaíno! ¿De dónde saca la Ponencia que la Rioja es Guipúzcoa? [...] El Club riojano en Guipúzcoa es algo así como un parche en un tambor nuevo: sin que ello signifique demérito en la calidad del parche. $\mathrm{Ni}$ en la del tambor, que tan a gusto redoblan, por lo visto, los de la ponencia ${ }^{37}$.

Estas cuestiones ya fueron visibles, por ejemplo, en la organización de competiciones locales como la Copa Vasca: una competición que se proyectó con el principal objetivo de presionar a la RFEF y hacer valer los intereses de los equipos guipuzcoanos a la hora de disputar el campeonato de España, a saber, evitar largos desplazamientos y hacerles partícipes de los beneficios de su grupo. Sin embargo, por uno u otro motivo, es decir, al margen de que se organizara la competición vasca o que se respetaran finalmente los intereses de los guipuzcoanos por parte de la RFEF, hubo clubs que mostraron su descontento por la inclusión del Deportivo Logroño. El Real Unión de Irún, por ejemplo, se quejó enérgicamente por tener que competir contra el club riojano porque éste no ofrecía compensación económica y porque la contienda no constituía «atracción para los aficionados» ${ }^{38}$.

Fruto de esta problemática, durante el agosto de 1928, se llegó a cuestionar que el Deportivo Logroño hubiera ascendido a la primera categoría de la Federación de Guipúzcoa cuando hubo entidades deportivas que adujeron que el C. D. Logroño no tenía la suficiente antigüedad como para ostentar la categoría: una artimaña de determinados clubs, entre los que se encontraban el Real Unión

\footnotetext{
${ }^{36}$ Excelsior, 21 de agosto de 1928, p. I.

37 Excelsior, 21 de agosto de 1928, p. I.

38 Euzkadi, 23 de agosto de 1928, p. 4.
} 


\section{DAVID MOTA ZURDO - JAVIER ZÚÑIGA CRESPO}

de Irún y el Tolosa F.C. que se veían amenazados por la irrupción del coloso futbolístico riojano. Zancadilla salió en defensa del club logroñés en las páginas de Excelsior:

En cuanto a lo de Clubs como Logroño, que solo cuentan con cuatro años de existencia, la Federación Guipuzcoana se olvida de que el Deportivo Logroño es una continuación del Recreation, que fue fundado y dado de alto el año 19/2. La antigüedad de Logroño en la Federación no quiere reconocerse ahora, y éste figuraba ya en la llamada Federación del Norte, domiciliada en Irún, y pasó a Guipúzcoa cuando ésta se fundó; por lo tanto, Logroño fue uno de sus fundadores. ¡Qué pronto ha olvidado la Federación Guipuzcoana la carta que con fecha 26 de enero del corriente año, con motivo de la adhesión de Logroño a Guipúzcoa, envío al C. D. Logroño! ¡Qué diferencia! La gratitud es patrimonio de los agradecidos y esta no se ha cobijado jamás en los pechos desposeídos de nobleza. Siendo fundadores de la Federación Guipuzcoana, se atreve un osado a llamarnos intrusos. Los méritos adquiridos por el Club Deportivo Logroño son innumerables, su cada vez más numerosa lista de socios, su campo de juego, que no solamente reúne las condiciones señaladas por la Real Federación Española de Foot-ball en sus artículos 19 y 45, si que también es el mejor de la Federación y uno de los mejores de España. Estos esfuerzos y sacrificios los viene realizando Logroño desde mucho antes de formarse la Federación Guipuzcoana, persiguiendo siempre el fin de escalar la superior categoría, a la que ha llegado ostentando siempre los títulos de campeón de la categoría inferior inmediata. ¿Qué equipo de los tres postergados supera o igual en méritos a los adquiridos por el Club Deportivo Logroño? Sobre todo, Logroño no niega a nadie la defensa de sus intereses, pero ésta sería siempre más noble exponiendo sus propios méritos, no quitándoselos al vecino que para nada se ha metido con ellos ¿Estamos? ${ }^{39}$

Este tipo de problemas no eran nuevos para una federación ya avezada en recibir críticas. Entre 1920 y 1928, Osasuna, adscrito también a la Federación Guipuzcoana de Fútbol, se vio inmerso en numerosos conflictos con clubes como la Real Sociedad de San Sebastián y la propia federación que superaron la mera rivalidad deportiva. Según los especialistas, las disputas llegaron a ser de carácter político debido al progresivo ascenso del club navarro, que se mostró como un competidor de primer orden frente a los guipuzcoanos. Ello redundó en problemas para los pamploneses. Osasuna se quejó en varias ocasiones por el nombre de la institución, que no representaba a todos los clubes. Siempre denunció la parcialidad de la federación en sus decisiones, que benefició a los clubes guipuzcoanos y que en determinados periodos conllevo obstáculos para el ascenso de división de los navarros. Prueba de ello es que en 1926 un club como el Tolosa F.C. propusiera a la federación la expulsión de Osasuna: el control guipuzcoano

39 Excelsior, 26 de agosto de 1928, p. 2. 


\section{EL FÚTBOL RIOJANO EN EL SIGLO XX}

de la institución era total. En 1921 la prensa osasunista ya había dejado patente esta circunstancia al recomendar la unión de navarros y riojanos en una federación propia y así «hacer frente a la insolente actitud de los semidioses que pretenden regir el cotarro deportivo» ${ }^{40}$.

Así, en 1928, hubo diferentes proyectos nonatos como el intento de crear una Federación Navarro-Alavesa que contribuyera a reestructurar los distintos campeonatos federativos vascos. Sin embargo, tras esos intentos, sumado a la creación de la Federación Navarra, los clubs de la serie A guipuzcoana se reunieron para estudiar cómo dar solución al problema del número de equipos que componían la competición. De este modo, contando con el plácet de la RFEF llegaron al acuerdo de que fueran cinco clubs en vez de cuatro los que compusieran la serie A guipuzcoana. A los ya presentes (Real Sociedad, Real Unión, Tolosa y Deportivo Logroño) se les unió el Pasayako guipuzcoano, que había resultado vencedor de la liguilla jugada por este, el Esperanza de San Sebastián y la Unión Deportiva de Éibar para dirimir que club ascendería de categoría ${ }^{41}$.

Una vez solucionado este incómodo tema para el Deportivo Logroño, la prensa vasca, incluida la nacionalista, realizó un viraje significativo en sus valoraciones del club riojano al que dedicó largas crónicas y artículos. Así, Euzkadi publicó en octubre de 1928 cuál era la composición de la junta directiva del club, que se cita a continuación. En el suelto se señaló el número de partidos jugados - con victorias, empates y derrotas, así como número de goles- y se cifró en 1700 el número de socios de la entidad:

Presidente honorario, don Germán Álvarez; presidente, don Bernardo Ardanaz; vicepresidente don Simeón Tejada; tesorero, don Jacinto Garrigosa; contador, don Práxedes Toledo; secretario, don Alfonso Torres; vocales: don Luis Ruiz Mosso, don Manuel Sánchez-Herrero Alba, don Fermín Alamo, don Rodolfo Jiménez, don Juan A. Ruíz Olalla, don Vicente Sáinz Marco, don Longinos Anguiana y don Basilio Surroca Ortíz de Zárate. Desde su fundación ha jugado el Deportivo Logroño 121 partidos, de los que ha ganado 84 , empató 16 y perdió 21 , habiéndose marcado 369 goals a favor por 142 en contra ${ }^{42}$.

En la temporada 1928-1929, compitiendo en la serie A guipuzcoana con una participación destacada y a pleno nivel, el C. D. Logroño acabó en segunda posición, por detrás de la Real Sociedad de San Sebastián. Asimismo, tuvo derecho a disputar el Campeonato de España. En su primera eliminatoria se enfrentó

\footnotetext{
40 Leoné, 200I, pp. 184-186.

41 Excelsior, 23 de septiembre de 1928, p. 2; Excelsior, 28 de septiembre de 1928, p. I. Sobre la problemática federativa ver Leoné, 200I, pp. 179-192.

42 Euzkadi, 4 de octubre de 1928, p. 4.
} 


\section{DAVID MOTA ZURDO - JAVIER ZÚÑIGA CRESPO}

al Betis. Aunque perdió en el partido de ida celebrado en Sevilla, eliminó al conjunto hispalense tras una gran actuación de Escolá, Juliac y Miguelín. Sin embargo, no superó la segunda ronda, donde fue literalmente arrollado por el Real Madrid con un cómputo global de trece goles a favor de los madrileños y cero de los riojanos ${ }^{43}$.

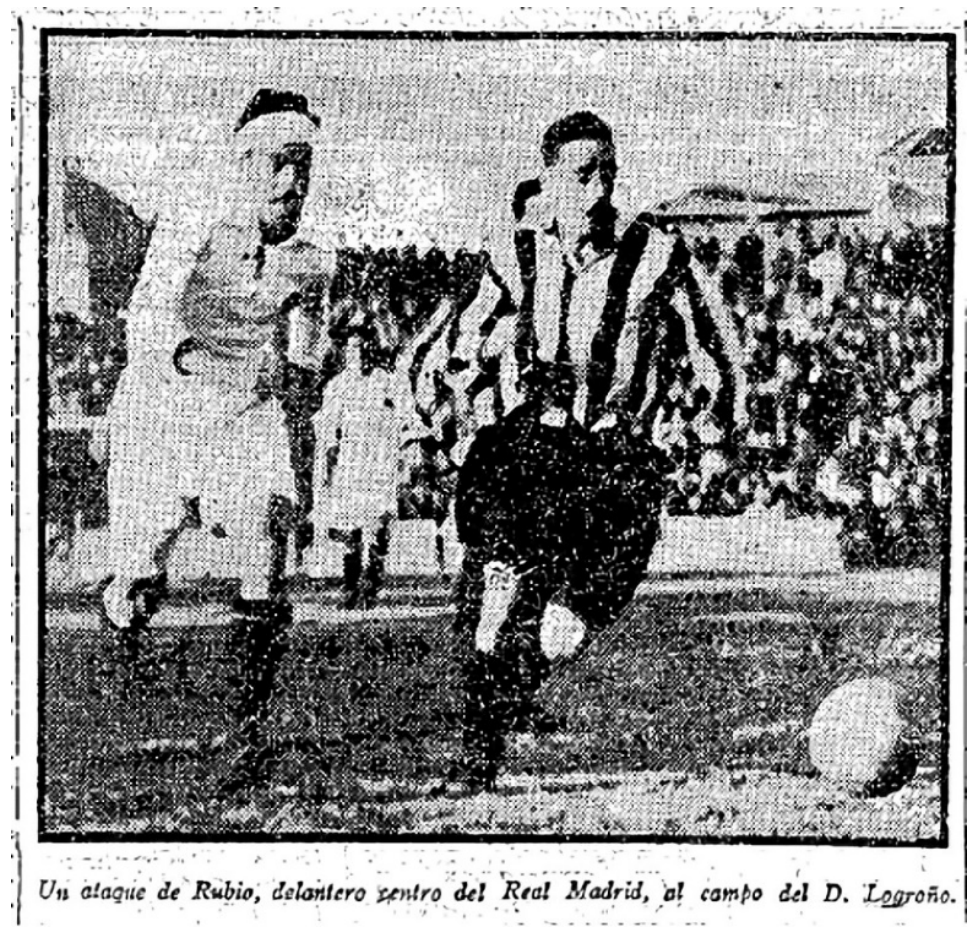

Figura I. Real Madrid-Logroño en Las Gaunas. Fuente: Excelsior, 25-XII-1928, p. 3.

En 1929 también participó en el torneo de ascenso a la Segunda División del Campeonato de Liga. En enero de ese año se enfrentó al Gimnástico de Valencia, saliendo derrotado por dos goles a uno e, igualmente, perdió contra el Baracaldo por tres goles a dos. Las esperanzas depositadas por el club riojano en la promoción a Segunda se vieron truncadas y, por eso, la presión a la que había sido sometido el equipo, tras perder contra el Gimnástico, fueron palpables en

\footnotetext{
${ }^{43}$ Excelsior, II de diciembre de 1928, p. 3; Euzkadi, 18 de diciembre de 1928, p. 7; Excelsior, 25 de diciembre de 1928, p. 3; Euzkadi, I de enero de 1929, p. 3.
} 


\section{EL FÚTBOL RIOJANO EN EL SIGLO XX}

el partido contra el conjunto vizcaíno cuando estando próximos al final del encuentro y yendo por detrás en el marcador, los jugadores de ambos equipos se convirtieron en «combatientes», propinándose todo tipo de «leñazos» y «amenazas» que fueron «verdaderamente detestables», según la prensa bilbaína ${ }^{44}$.

En Excelsior se ofrecieron algunas de las claves de aquella derrota:

[...] la compenetración del Deportivo Logroño es cosa que ha pasado a la historia, y es muy difícil que volvamos a ver a los futbolistas logroñeses en aquel acoplamiento de líneas y rivalidad colectiva de codicia que fueron la causa principal de sus resonantes triunfos primeros. En cuanto a esas plausibles condiciones sustituyeron las diferencias entre los jugadores las tiranteces y celos, la moral decayó manifiestamente y todos los optimismos, que antes despertara la actuación del equipo blanquirrojo han cedido el puesto a un general pesimismo, o, por lo menos, a una total ausencia de esperanzas ${ }^{45}$.

Durante la temporada 1929-1930, el Deportivo Logroño quedó en cuarta posición, no pudiendo, por ello, participar en el campeonato de España. Asimismo, fue incluido en una nueva división, la Tercera, un torneo paralelo al campeonato liguero regional en el que compitió contra el Baracaldo, Valladolid, Torrelavega y Sestao, sin que ello supusiera cambios de categoría, pues siguió militando en la serie A. En el campeonato de 1930-1931 quedó en segunda posición y se clasificó para el campeonato de España, en el que realizó una buena participación: eliminó a la Cultural Leonesa, el Valladolid y el Castellón, pero en semifinales perdió contra el Athletic Club de Bilbao, a la postre, campeón de la competición. Igualmente, en el torneo de la Tercera se quedó a un punto del Baracaldo, que fue el que en última instancia jugó la fase de ascenso a Segunda ${ }^{46}$.

\section{CONCLUSIONES}

A lo largo de este trabajo, se ha visto cómo el fútbol comenzó a desarrollarse en La Rioja durante la Restauración y se ha identificado al Logroño Recreation Club como entidad fundamental a la hora de asumir el rol de impulsora de este deporte en la región. A esta consolidación ayudó el viraje de la prensa respecto al fútbol, no solo ya en la ausencia de críticas, como las que habían estado realizando años atrás, sino en el seguimiento y difusión de todo lo relacionado con ello, favoreciendo la aparición de nuevos aficionados, que, en última instancia, derivó en un crecimiento del número de socios. En lo concerniente a sumar

\footnotetext{
${ }^{44}$ Euzkadi, 6 de enero de 1929, p. 3. El Liberal, 15 de enero de 1929, p. 7.

45 Excelsior, 16 de enero de 1929, p. 2.

46 Prudencio y Arraiz, 1990, pp. 9-10.
} 


\section{DAVID MOTA ZURDO - JAVIER ZÚÑIGA CRESPO}

adeptos, fue determinante que Recreation Club se volcará en ofrecer instrumentos de retroalimentación identitaria al asociar la entidad con la ciudad a la que representaba y, por tanto, con sus habitantes (la masa de potenciales seguidores) creando unos colores y una simbología propias del territorio.

Esta base social de aficionados fue la que permitió, en el momento en el que desapareció el Recreation Club, que un nuevo proyecto, el del Club Deportivo Logroño, contase con apoyo desde el comienzo, heredando buena parte de la afición. Si se ha señalado que una de las labores más importantes del Recreation fue la creación de una identidad a través de los símbolos, el Club Deportivo Logroño dio un paso más allá con la construcción del estadio de fútbol de Las Gaunas. Un estadio en propiedad que contribuyó a acabar con los problemas sufridos en el campo de La Trilladora y, a su vez, se convirtió en la insignia del fútbol en Logroño: un lugar reconocible por aficionados y rivales. La aparición de prensa especializada en el Deportivo Logroño entre 1927 y 1928 dan prueba, como se ha visto en este trabajo, tanto de estas cuestiones como del interés creciente por el club y sus resultados, lo que es comprensible si se atiende al buen hacer que tuvo el equipo durante estos años.

No obstante, como se ha visto, también hubo dificultades, entre ellos, los problemas federativos. De su análisis se puede concluir que la distancia geográfica entre Logroño y el resto de las localidades que formaban la Federación Guipuzcoana generó quejas por parte de los equipos por los gastos de desplazamiento: a los equipos de Irún y Deba, por ejemplo, les molestó tener que invertir el dinero de sus arcas en la visita a una ciudad «ajena» a su territorio. Esto, unido al carácter elitista de los equipos vascos y la consideración del team riojano como foráneo a su región - anteriormente se ha citado en Excelsior esta ácida metáfora «el Club riojano en Guipúzcoa es algo así como un parche en un tambor nuevo: sin que ello signifique demérito en la calidad del parche»- generó un ambiente enrarecido que la reforma Cabot terminó por destapar.

Por la vía deportiva era imposible poner en duda la participación del Deportivo Logroño en la Serie A, ya que los resultados le acompañaban, aunque el asunto de la antigüedad abrió una puerta a la reclamación. Zancadilla, en su opinión, zanjó el asunto de manera sencilla, unificando las edades de Recreation Club y Deportivo Logroño como un solo ente. Hay razones para plantear la existencia de una línea continuista, como se ha mostrado en el artículo. Sin embargo, conviene la prudencia: Zancadilla al señalar esto tenía sus propios intereses como era la defensa del Deportivo Logroño. Sin olvidar, además, que las fuentes no refrendan el hecho que el cronista aseveró.

Los años 1923 a 193I fueron de irregularidad, tanto en el plano deportivo como a nivel de organización. El Deportivo Logroño pasó, en pocos años, de plantear dudas sobre la viabilidad del proyecto deportivo a competir y cosechar 


\section{EL FÚTBOL RIOJANO EN EL SIGLO XX}

buenos resultados contra grandes equipos. En buena manera, su situación fue fruto del contexto: las discusiones federativas sobre cómo organizar la competición en torno a si la región riojana debía competir en otras federaciones como las de Castilla o Aragón; los problemas económicos; el señalamiento extradeportivo como equipo foráneo; el amateurismo o los irregulares resultados obtenidos fueron a la postre determinantes en su trayectoria deportiva en las series A y B. De hecho, en el periodo de la Segunda República, los problemas del Deportivo Logroño con la Federación Guipuzcoana continuarían, como también la irregularidad en los resultados deportivos, con grandes triunfos (participación en el campeonato de España incluido) y fracasos sonados con derrotas muy duras contra equipos de primer nivel como el Real Madrid y el Athletic Club de Bilbao.

La historia del Club Deportivo Logroño durante la Segunda República, una etapa tan reformista como convulsa en lo deportivo, precisa de ser estudiada en toda su complejidad y atendiendo a las claves de la época, alejadas tanto del contexto como del objetivo de esta investigación: dar a conocer el fútbol en Logroño durante su etapa fundacional a través de Logroño Recreation Club y Club Deportivo Logroño. Toca, pues, que los investigadores recojan el testigo que aquí se brinda y realicen una investigación exhaustiva sobre el fútbol en Logroño durante la Segunda República.

\section{BIBLIOGRAFÍA}

Andrés, Sergio y Javier Castro, La pelota en La Rioja, Logroño, Gobierno de La Rioja, 201 I. Báez, José María, «El Real Madrid y el origen del fútbol como espectáculo de masas, 1923 1936», Historia y comunicación social, 17, 2012, pp. 159-180.

Barbero, José Ignacio, «Deporte y cultura: de la modernidad a los discursos posmodernos del cuerpo», Educación Física y deporte, 25, I, 2006, pp. 69-93.

Barbero, José Ignacio, «El darwinismo social como clave constitutiva del campo de la actividad física educativa, recreativa y deportiva», Revista de Educación, 359, 2012, Pp. 580-603.

Bermejo, Francisco, La II República en Logroño. Ocio y Espectáculos, Logroño, Piedra de Rayo, 2009.

Calatayud, Francisco, Evolución de la educación fisica y el deporte en España a través de la revista «Apunts» (1964-1993), Valencia, Universitat de Valencia, 1998.

Calatayud, Francisco, De la gimnasia de Amorós al deporte de masas (I 770-1993): una aproximación histórica a la educación fisica y el deporte en España, Valencia, Ayuntamiento de Valencia, 2002.

Camino, Alejandro, «Jugando contra la 'furia española' (1910-1936)», Studia historica. Historia contemporánea, 37, 2019, Pp. II9-137.

Cañas, Sergio, «El ferrocarril en La Rioja. De la industria privada a la nacionalización, |878-1936» en Un viaje sobre raíles. La Rioja (I863-20|3), ed. José Miguel Delgado, Logroño, IER, 20I3, pp. |4|- 68. 


\section{DAVID MOTA ZURDO - JAVIER ZÚÑIGA CRESPO}

Caspistegui, Francisco Javier y John K. Walton, Guerras danzadas. Fútbol e identidades locales y regionales en Europa, Pamplona, EUNSA, 200I.

Caspistegui, Francisco Javier, «Osasuna y Navarra entre la primera y la segunda división», en Guerras danzadas. Fútbol e identidades locales y regionales en Europa, ed. Francisco J. Caspistegui y John K. Walton, Pamplona, EUNSA, 200I, pP. 193-2I4.

Caspistegui, Francisco Javier, «La resbaladiza arista de un monte erguida sobre dos abismos: mujer y deporte en España (1900-1950)», Memoria y civilización, 7, 2004, pp. 129-174.

Caspistegui, Francisco Javier, «Deporte e identidad, o sobre cómo definirnos», Historia y Comunicación Social, 17, 2012, pp. 19-39.

Caspistegui, Francisco Javier y Santiago Leoné, Cien años de relación entre los navarros y el deporte (I90I-200I), Pamplona, EUNSA, 2010.

Castro, Javier, «La Rioja y la pelota», Berceo, 169, 2015, pp. I35-I48

Cidoncha, Antonio José, Arquitectura, deporte y sociedad. Los estadios de fútbol en España. 1940-1960, Pamplona, Universidad de Navarra, 2018.

Ciria, Pedro, El sueño de ser grandes: historia social del nacimiento del fútbol en Zaragoza, 1903-1936, Zaragoza, Universidad de Zaragoza, 2012.

Climent, Eugenio Antonio, «Industria y planificación urbana: el caso de Logroño», Berceo, I4I, 200I, pp. 213-228.

De la Fuente, Fernando y Josep Calvera, La Rioja y su ferrocarril, Logroño, Bodegas MugaAsociación de Amigos del Ferrocarril de la Rioja Alta, 2014.

De Lucas, José María, Historia de la educación fisica oficial: España 1900-1936, Madrid, UNED, 1998.

De Pablo, Santiago, Deportivo Alavés. 100 años de historia (I92 I-202I), Vitoria-Gasteiz, Deportivo Alavés S.A.D., 2020a.

De Pablo, Santiago, «Fútbol e identidad local. Un estudio de caso: Dmitry Piterman y el museo del Deportivo Alavés», Sancho el Sabio, Extra 3, 2020b, pp. 235-257.

Domínguez, Andrés, Historia social do deporte en Galicia: cultura deportiva e modernidade, 1850-1920, Vigo, Galaxia, 2009.

Estomba, Fernando, Deporte, politica y sociedad en Vizcaya: afición y espectáculos en la segunda república y en la guerra civil, Bilbao, UPV-EHU, 2007.

Fernández, Andoni, «Los orígenes del Sport en Logroño. Notas para una historia del deporte en La Rioja», Berceo, 146, 2004a, Pp. 22I-236.

Fernández, Andoni, Los espacios de sociabilidad en Logroño a comienzos del siglo XX. Una aproximación a la historia del ocio, Logroño, IER, 2004b.

Fernández, Carlos, El fútbol durante la Guerra Civil y el franquismo, Madrid, San Martín, 1990.

Fernández-Sirvent, Rafael, «Memoria y olvido de Francisco Amorós y de su modelo educativo gimnástico y moral», RICYDE. Revista Internacional de Ciencias del Deporte, 3, 6, 2007, pp. 24-5I.

Fernández, Juan Carlos y David Rodríguez, «El nacimiento de un deporte, el Pedestrarismo», Revista Española de Educación Física y Deportes. REEFD, 402, 2013, Pp. III122. 


\section{EL FÚTBOL RIOJANO EN EL SIGLO XX}

Gallardo, Francisco, «Apuntes para una historia contemporánea de la Medicina del Deporte en España», MD. Revista de medicina del deporte, 5, 2006, pp. 35-40.

García Bonafé, Milagros, «Notas para una historia del deporte en España», Revista de Occidente, 62-63, 1986, pp. 35-50.

Gil, Rodrigo, La prensa deportiva. Periodo de entreguerras en España (siglo XX), Madrid, Universidad Complutense, 2004.

González, Teresa, Introducción del deporte en España: su repercusión en el arte, Madrid, Edilupa, 2003.

Gounot, André, «El proyecto de la olimpiada popular de Barcelona (1936), entre Comunismo internacional y republicanismo regional», Cultura, ciencia y deporte, I, 3, 2005, pp. II5-123.

Ibarnavarro, Andrés, Pueblos de La Rioja. Briones, Zaragoza, Heraldo de Aragón, 1946.

Iturriaga Barco, Ángel, El poder político y social en la historia del Fútbol Club Barcelona (I 8992015), Logroño, Universidad de La Rioja, 2015.

Izquierdo Macón, Eugenio, La bicicleta en la España del último cuarto del siglo XIX, Las Palmas de Gran Canaria, Universidad de Las Palmas de Gran Canaria, 200I.

Lagardera, Francisco, «Notas para una historia social del deporte en España», Historia de la Educación: revista interuniversitaria, I4-I5, 1995-1996, PP. I5I-I72.

Leiva, Ricardo, Análisis de participación y resultados del Equipo Olímpico Español en los Juegos Olímpicos de verano (I896-2008), Alicante, Universidad de Alicante, 2012.

Leoné, Santiago, «Fútbol e identidad local: las disputas en la Federación Guipuzcoana de fútbol (1920-1928)» en Guerras danzadas. Fútbol e identidades locales y regionales en Europa, ed. Francisco J. Caspistegui y John K. Walton, Pamplona, EUNSA, 200 I, PP. 179-192.

López, Pedro, «Reforma agraria y revolución liberal en Logroño durante la Edad Contemporánea», Brocar: cuadernos de investigación histórica, 23, 1999, pp. 167-215.

Lorenzo Calvo, Beatriz, Origen y evolución histórico-legal del club deportivo en la Comunidad de Madrid (I833-1936), Madrid, Universidad Politécnica de Madrid, 2016.

Martialay, Félix, La implantación del profesionalismo en el fútbol español y el nacimiento accidentado del torneo de liga, Madrid, Real Federación Española de Fútbol, 1996.

Martínez, Lucio, «A vueltas con la historia: una mirada a la educación física escolar del siglo XX», Revista de Educación, Extra-I, 2000, pp. 83-I I 2.

Martínez, María Eugenia, «Educación Física y medicina: una historia compartida y simbiótica», Revista Internacional de medicina y Ciencias de la Actividad Física y del Deporte, 3, 9, 2003, pp. 30-48.

Mateos, María José, «Educación física en las normales de Badajoz, 1900-1975: estudio estadístico», Revista Española de Educación Física y Deportes: REEFD, 393, 20I I, PP. 69-88.

Mestre, Juan Antonio, La educación fisica en la medicina española (I850-1936): su utilización en la prevención de la enfermedad y en la promoción de la salud. Aproximación histórica, Valencia, Universitàt de València, 1996.

Moreno, José Ramón y Agustín Sancho, «Especialización flexible y modelos empresariales en el valle medio del Ebro, I880-1935», Información Comercial Española, ICE: Revista de Economía, 8,12, 2004, pp. 199-209. 


\section{DAVID MOTA ZURDO - JAVIER ZÚÑIGA CRESPO}

Mota, David, «Haro Sport Club: origen, estabilización y primeros campeonatos (19211924)», Berceo, 176, 2019a, pp. 9-34.

Mota, David, «Los pioneros del fútbol riojano: Agrupación Deportiva Gran Casino y Logroño Recreation Club (1900-1920)», Materiales para la historia del deporte, 19, 2019b, pp. 78-93.

Mota, David, «La pelota riojana ante la sociedad de masas: un acercamiento a sus orígenes y evolución (I890-1910)», Berceo, 178, 2020a, Pp. 137-160.

Mota, David, «El ciclismo riojano en el siglo XX: Logroño como motor deportivo (19001920)», Citius altius, fortius: humanismo, sociedad y deporte: investigaciones y ensayos, 13, I, 2020b, pp. 19-35.

Mota, David, Entre la pasión y la gloria: el fútbol riojano a través de Haro Sport Club (19/31929), Logroño, IER, 2020c.

Mota, David, «La educación física, los gimnasios y la práctica deportiva a través del diario La Rioja (1890-1920)», Brocar: cuadernos de investigación histórica, 44, 2020d, pp. 195-2I2.

Mota, David, «El velocipedismo/ciclismo en La Rioja en el siglo XIX: sobre el origen e historia de las sociedades Veloz Club Riojano de Logroño y Club Velocipedista Harense», Materiales para la historia del deporte, 20, 2020e, pp. 39-53.

Muntión, Carlos, 50 años de pelota en La Rioja: Federación Riojana de Pelota (1943-1993), Logroño, Federación Riojana de Pelota, 1993.

Olivera, Javier, José María Cagigal Gutiérrez (1928-1983): vida, obra y pensamiento en torno a la educación fisica y el deporte, Barcelona, Universitàt de Barcelona, 1997.

Otero, Luis Enrique, "Ocio y Deporte en el nacimiento de la sociedad de masas. La socialización del deporte como práctica y espectáculo en la España del primer tercio del siglo XX»), Cuadernos de Historia Contemporánea, 25, 2003, pp. 169-198.

Otero, Luis Enrique, «La sociedad urbana y la irrupción de la Modernidad en España (1900-1936)», Cuadernos de Historia Contemporánea, 38, número especial, 2016, Pp. 255-283.

Pastor, José Luis, El espacio profesional de la educación fisica en España: génesis y formación (I883-196I), Alcalá de Henares, Universidad de Alcalá, 1997.

Pinheiro, Francisco, «Portugal, España y el fútbol. La construcción histórica de una amistad», Arbor: Ciencia, pensamiento y cultura, 766, 20I4, pp. 2-I0.

Prudencio, Esteban y Jesús Arraiz, Club Deportivo Logroñés (cinco décadas de fútbol). I Parte: de 1940 a 1964. Logroño, Rioja 7 días, 1990.

Pujadas, Xavier (coord.), Atletas y ciudadanos. Historia social del deporte en España, I8702010, Madrid, Alianza, 20II.

Pujadas, Xavier y Carles Santacana, «La mercantilización del ocio deportivo en España: el caso del fútbol, 1900-1928», Historia Social, 4I, 200I, pp. 147-I68.

Pujadas, Xavier y Carles Santacana, «El club deportivo como marco de sociabilidad en España: una visión histórica (1850-1975)», Hispania: Revista española de historia, 63, 2।4, 2003, pp. 505-522.

Pujadas, Xavier y Aleix Augé, «La institucionalización del deporte en plena guerra civil. La creación del instituto de educación física y deportes de Cataluña de 1937», 


\section{EL FÚTBOL RIOJANO EN EL SIGLO XX}

Athlos: Revista Internacional de Ciencias Sociales de la actividad fisica, el juego y el deporte, 3, 2012, pp. 123-143.

Quiroga, Alejandro, Goles y banderas: fútbol e identidades nacionales en España, Madrid, Marcial Pons, 2014.

Quiroga, Alejandro, «Así también se hace Patria. Fútbol y franquismo en Cataluña y el País Vasco (1939-1977)», Hispania Nova: Revista de historia contemporánea, I7, 2019, pp. 270-302.

Quirós, Ana María, El deporte en la Medicina Española (1900-1975). Su estudio como causa y como tratamiento de la enfermedad en las revistas médicas, Valencia, Universitàt de València, 2010.

Riaño, Catalina, Historia cultural del deporte y la mujer en la España de la primera mitad del siglo XX a través de la vida y obra de Elía María González Álvarez y López Chicheri, «Lilì», Madrid, Consejo Superior de Deportes, 2004.

Riaño, Catalina y Concepción Carbajosa, «Proceso histórico de la incorporación de la mujer española a la práctica deportiva en el primer tercio del siglo XX. Conceptualización a través de la prensa escrita de la época», Citius, Altius, Fortius: humanismo, sociedad y deporte: investigaciones y ensayos, 2, I, 2009, Pp. 23-47.

Rivero, Antonio, Deporte y modernización. La actividad fisica como elemento de transformación social y cultural en España, 1910-1936, Sevilla, Wanceulen, 2005.

Robert, Miquel, «Nemesi Ponsati: un pedagogo del deporte», Citius, altius, fortius: humanismo, sociedad y deporte: investigaciones y ensayos, 3, 2, 2010 , pp. 52-6I.

Shaw, Duncan, Néstor Míguez y Paul Preston, Fútbol y franquismo, Madrid, Alianza, 1987.

Simón, Juan Antonio, «El papel de la mujer en el origen y desarrollo del deporte en España (1900-1939)» en Actas del Primer Congreso Internacional «Las mujeres en la Esfera Pública, Filosofía e Historia Contemporánea», coord. Laura M. Branciforte, Carmen González y Montserrat Huguet, Madrid, Compañía Española de Reprografía y Servicios, 2009, pp. 77-102.

Simón, Juan Antonio, La marea del deporte: fútbol y modernización en los orígenes de la sociedad de masas en España, 1900-1936, Madrid, Universidad Carlos III, 201 I.

Simón, Juan Antonio, «Conquistando a las masas: el impacto del deporte en la prensa española, 1900-1936», Recorde: Revista do História do Esporte, 5, I, 2012a.

Simón, Juan Antonio, «Fútbol y cine en el franquismo: la utilización política del héroe deportivo en la España de Franco», Historia y comunicación social, 17, 2012b, pp. 69-84.

Simón, Juan Antonio, «Deportistas en las trincheras de Europa: la primera guerra mundial y su impacto en la prensa deportiva española», Podium: Sport, Leisure and Tourism Review, Sâo Paulo, 3, 2, 2014, pp. 97-III.

Simón, Juan Antonio, Construyendo una pasión: el fútbol en España, 1900-1936, Logroño, UNIR Editorial, 2015.

Simón, Juan Antonio, «Fútbol global e identidades nacionales en 1925: la gira del Club Atlético Boca Juniors en España a través de su impacto en la prensa», Historia Crítica, 6I, 2016, pp. 45-63.

Sirera, Carles, Cuando el fútbol no era el rey: los deportes en el espacio público en la ciudad de Valencia (I875-1909), Valencia, Universitat de València, 2008. 


\section{DAVID MOTA ZURDO - JAVIER ZÚÑIGA CRESPO}

Souto, Sandra, «Las diferentes "caras" de la modernización: juventud y movilización» en Regeneracionismo autoritario. Desafios y bloqueos de una sociedad en transformación: España, 1923-1930, ed. Francisco Villacorta y María Luisa Rico, Madrid, Biblioteca Nueva, 2013, pp. 163-178.

Tierra, José María, «Los primeros Juegos Atléticos en España: Huelva-1890», Materiales para la Historia del deporte, 5, 2007, pp. 53-59.

Torrebadella, Xavier, «Aproximación a una historia de la actividad física y el deporte mediante el análisis de las fuentes bibliográficas (1800-1939)», Apunts: Educación fisica y deportes, 59, 2000, pp. II-2I.

Torrebadella, Xavier, Contribución a la historia de la educación fisica en España. Estudio biobibliográfico en torno a la educación fisica y el deporte (1800-1939), Lleida, Universitat de Lleida, 2009.

Torrebadella, Xavier, «Orígenes del fútbol en Barcelona (1892-1903)», RICYDE. Revista Internacional de Ciencias del Deporte, 8, 27, 2012, pp. 80-102.

Torrebadella, Xavier y Antoni Nomdedeu, «La popularización del fútbol en España. Análisis del fenómeno a través de la literatura especializada del fútbol (1920-1936)», Revista general de información y documentación, 26, I, 2016, pp. II9-146.

Torrebadella, Xavier y Carlos Martínez, «El nacimiento del fútbol en España: ¿cómo se entrenaba y cómo se jugaba? I Iarte (I899-1920)», Recorde: Revista do Histórica do Esporte, I3, I, 2020.

Uría, Jorge, Una historia social del ocio. Asturias I898-19/4, Gijón, UGT, 1996.

Uría, Jorge, «El nacimiento del ocio contemporáneo», Historia Social, 4I, 200I, pp. 65-68.

Uría, Jorge, «lmágenes de la masculinidad: el fútbol español en los años veinte», Ayer, 72, 2008, pp. 121-155.

Vizuete, Manuel, La educación fisica y el deporte escolar durante el franquismo, Madrid, UNED, 1996.

Vizuete, Manuel, «Los valores del deporte en España. Del Regeneracionismo a la Guerra Civil», Revista Española de Educación Física y Deportes, Madrid, II, 2009, pp. 25-46.

Yanes, Julio Antonio, «El maridaje fútbol/radiodifusión en las Islas Canarias durante el franquismo, 1939-1975», Revista Internacional de Historia de la Comunicación, 5, 2015, pp. 164-186.

Zambrana, Manuel, Historia y evolución del deporte en España: desde la educación fisica de Amorós a la gestión del siglo XXI, Madrid, Círculo de Gestores, 2005. 